\title{
AN EPIDEMIO-COPROLOGICAL STUDY OF PROTOZOAN AND NEMATODE PARASITES OF RUMINANTS IN TROPICAL SEMI-ARID DISTRICT OF SOMALILAND (NORTHERN OF SOMALIA)
}

\author{
Yasser M. Ghanem ${ }^{1,3}$, Mohamed H. Naser ${ }^{1}$, \\ Ahemd H. Abdelkader ${ }^{2}$, Ahemd Heybe ${ }^{3}$
}

\begin{abstract}
${ }^{1}$ Department of Animal Medicine, Faculty of Veterinary Medicine, Kafrelsheikh University, Kafr Elsheikh, Egypt.

${ }^{2}$ Laboratory of the Gulf Veterinary International Quarantine Management Company, Berbera, Somaliland, Somalia.

${ }^{3}$ Ministry of Livestock and Animal health, Somaliland, Somalia.
\end{abstract}

\begin{abstract}
The present study showed that the prevalence of gastrointestinal parasites in overall studied ruminants (cattle, sheep and goats) where highest with Trichsrtongylus Axei 26.9\% (n=343), Lungworm (Dictyocaulus spp.) 9.8\%, $(n=125)$, Eimeria (Coccidia) $7.2 \%(n=92)$, Ascaris (Neoscaris vitulorum) $3.6 \% \quad(n=14)$, and Homonchus contortus $2.3 \% \quad(n=30)$ respectively. For cattle, the overall prevalence was $30.9 \%(n=120)$ with highest by Trichsrtongylus Axei $22.9 \%(n=89)$, Ascaris $3.6 \%(n=14)$, Lungworm $2.3 \%(n=9)$ and Homonchus $2.1 \% \quad(n=8)$ respectively. For sheep, the overall prevalence was $60.7 \%(n=282)$ with highest by Trichsrtongylus Axei $30.5 \%$ (n=142), Lungworm $17.8 \%(n=83)$, Eimeria 9.3\% $(n=43)$, and Homonchus $2.6 \%(n=14)$ respectively. For goats, the overall prevalence was $47.8 \%$ ( $n=202)$ with highest by Trichsrtongylus Axei $26.5 \%$ ( $n=112)$, Eimeria $11.6 \%(n=49)$, Lungworm $7.8 \%(n=33)$ and
\end{abstract}


Homonchus $1.9 \%(n=8)$ respectively. Prevlence difference were recorded in different studied regions where it was highest in Odweyne $54.2 \%$ ( $n=149)$, Burao 50.2\% (n=213), Sheikh 45.1\% ( $n=156)$, followed by Berbera 37.1\% $(n=86)$ respectively. According to sex, prevalence for females were higher $51.1 \%(n=342)$ than males $43.1 \%(n=262)$. For cattle, females were $34.3 \%(n=69)$ and males $27.1 \%(n=51)$. For sheep, females $63.9 \%(n=161)$ and males $56.8 \%$ $(n=121)$. For goats, females $51.9 \%(n=112)$ and males $43.5 \%(n=90)$ however, the higher prevalence in females was not significant than that of males. A statistically significant difference was found in prevalence and egg output (eggs per gram; EPG) among species of animals considered. A higher rate was recovered in small ruminants than in cattle, and a greater proportion of study animals had low EPG compared with study animals with moderate to severe EPG. The severity of infestation (EPG\%) in relation to species where examined for 1277 animals, overall prevalence was 47.3\% (n=604), low was $62.9 \%(n=380)$, moderate $26.7 \%(n=161)$, and severe was $10.4 \%$ $(n=63)$. Cattle examined were 389 with over all prevalence of $30.9 \%$ $(n=120)$ where the low degree was $68.3 \%(n=82)$, moderate $25.0 \%$ $(n=30)$ and severe was $6.7 \%(n=8)$. Sheep examined were 465 with over all prevalence of $60.7 \%(n=282)$ where the low degree was $61.7 \%(n=174)$, moderate $28.4 \%(n=80)$ and severe was $9.9 \%$ $(n=28)$. Goats examined were 423 with over all prevalence of $47.8 \%$ $(n=202)$ where the low degree was $61.4 \%(n=124)$, moderate $25.2 \%$ $(n=51)$ and severe was $13.4 \%(n=27)$. The $E P G \%$ vary among studied regions with high degree (severe) in Burao $6.1 \%(n=26)$ regions (highest than other regions and lowest severity were found in Berbera region $3.5 \%(n=8)$. The EPG\% vary between males and females with little significance. Season were shown to have association with prevalence but not with EPG while no association was revealed 
between prevalence and EPG with sex, age, and body condition of the animals. The EPG\% vary between Dry season (May to October) and wet season (November to April) with significant variance as it was much higher in wet season $54.1 \%(n=457)$ than in dry season $34.0 \%$ $(n=147)$. Hence, in this study, species of the animals, season, and sex are important risk factors associated with gastrointestinal parasites in the studied regions. It was found that the prevalence of internal parasitic infections was higher in sheep $60.7 \%(n=282)$ than in goats $47.8 \%$ ( $n=202)$. And small ruminant prevalence were higher than in cattle $30.9 \%(n=120)$. The most prevalent gastrointestinal nematode was in both host species Trichostrongylus axei.

Key Words: parasites, prevalence, risk factors, ruminants, gastrointestinal nematodes, Africa, tropical, epidemiology

\section{INTRODUCTION}

In general, gastrointestinal parasite infections are a world-wide problem for both small- and large-scale farmers, however, their impact is greater in sub-Saharan Africa. The prevalence of gastrointestinal parasites and the severity of infection vary considerably depending on the genera of helminth parasites involved, animal species, local environmental conditions such as humidity, temperature, rainfall, vegetation, and management practices. The variation dynamics of parasite population has been described in a number of studies in many African countries (Assoku, 1981; Vercruysse, 1985; Fakae, 1990; Fritsche, et al., 1993; Maingi, et al., 1993; Pandey, et al., 1994; Tilahun, 1995; Tembely, et al., 1997; Nginyi, et al., 2001; Debela, 2002; Van Wyk, 2004). However, in the humid tropical climate as in West Africa, the regions surrounding Lake Victoria and parts of coastal eastern Africa, the climatic conditions 
permit development of eggs and larval stages more-or-less continuously throughout the year where the optimal humidity requirement for free living stage development of most species is 85\% (Chiejina, et al., 1989; Hansen and Perry, 1994; Tembely, 1998; O'Connor, et al., 2006). Although desiccation is lethal for the free-living stages of parasite worms, the important nematode parasites can survive such conditions either as embroynated eggs or as infective larvae (Tembely, 1998; O'Connor, et al., 2006). Economic losses are caused by gastrointestinal parasites in a variety of ways, they cause losses through lowered fertility, reduced work capacity, involuntary culling, a reduction in food intake and lower weight gains, lower milk production, treatment costs, and mortality in heavily parasitized animals (Over, et al., 1992; Anon, 1994; Gatongi, et al., 1997; Nari, et al., 1997; Perry and Randolph, 1999; Perry, et al., 2002; Tibbo, et al., 2006). Endoparasites are responsible for the death of one third of calves, lambs and kids, and considerable losses of parts of carcasses condemned during meat inspection (Anon, 1997; Anon, 2000b). In Ethiopia as a neighbour country to Somaliland, the enormous losses resulting from inferior weight gains, lower milk yields and condemnation of organs and carcasses at slaughter due to parasitosis were recorded (Bekele, et al., 1992; Ngategize, et al., 1993; Tilahun, 1993). The Nemathelminthes (nematodes) include several superfamilies of veterinary importance. These are Trichostrongyloidea, Strongyloidea, Metastrongyloidea, Ancylostomatoidea, Rhabditoidea, Trichuroidea, Filarioidea, Oxyuroidea, Ascaridoidea and Spiruroidea. The most important strongylid nematodes of sheep and goats in African countries are: Haemonchus contortus, Teladorsagia circumcincta and Trichostrongylus spp.(T.axei, T. colubriformis and T. vitrinus). Hansen and Perry, 1994). All grazing sheep and goats are infected with a community of these 
strongylid nematodes, whose combined clinical effect is the condition known as parasitic gastroenteritis (PGE) (Zajac, 2006). The life cycles are direct, requiring no intermediate hosts, which applies to all of the economically important strongylid parasites of small ruminants (Hansen and Perry, 1994; Urquhart, et al., 1996). Haemonchus contortus is mainly a parasite of sheep and goats and sometimes cattle. Haemonchus are most dominant in summer rainfall areas. Trichostrongylus axei (stomach hair worm) occurs commonly in ruminants are perhaps the most important parasites of small ruminants world-wide, causing significant morbidity and loss of production. The L3 can survive for several months, but once hydrated they become active and rapidly exhaust their food reserves (Tembely, 1998; Torina, et al., 2004; O'Connor et al., 2006). Eimeria spp for example Eimeria zuernii and E. bovis in cattle (of small and large intestine) is a parasite of small and large intestines of cattle, sheep and goats. Oocyst counts may not correlate with severity of infection. Coccidiosis usually occurs in younger animals -or in adults introduced to higher rainfall areas from the drier pastoral zones - and with high stocking rates or overcrowding under wet and cool conditions. Dictyocaulus spp (large lungworm) causing verminous pneumonia, is mainly a disease of cool, moist climates (Cole, V.G. 1986; Jubb, et al., 1993; Smeal, 1995; McLeod, 1995). Fecal flotation procedures are used to separate parasites in all life stages (e.g. eggs, oocysts, sporocysts, cysts, larvae) from other objects and debris based on their different densities (specific gravity). Successful fecal flotation is based on the principle that when a fecal sample is placed in a sugar or salt solution, parasites less dense than the flotation solution will move to the top of the solution and parasites more dense than the solution will eventually settle to the bottom. Centrifugation forces the heavier objects to the bottom of the container sooner than the 
force of gravity alone does. Research has confirmed that centrifugal flotation is more effective than simple flotation in recovering parasites from fecal samples (Payne and Dryden, 2003, Dryden, et al., 2005; Dryden, et al., 2006). Fecal examination by means of the modified McMaster technique for the enumeration of worm eggs and larval differentiation by Fecal culture methods are the most common routine means for the diagnose helminthosis in small and lage ruminants with saturated sodium chloride solution as the floating medium (Anon, 1986; Hansen and Perry, 1994; Urquhart, et al., 1994; Kassai, 1999). The strongylid nematode genera produce eggs that are similar in appearance and cannot be easily discriminated, thus, Fecal cultures are required to yield L3 larvae, which generally can be differentiated to genus level (Anon, 1986; Hansen and Perry, 1994; Urquhart, et al.,1996; Kassai, 1999; Van Wyk, et al., 2004). Somaliland (northern Somalia) lies within the tropical latitudes of Africa, and has an extremely diverse topography, a wide range of climatic features and a multitude of agro-ecological zones which makes the country suitable for different agricultural production systems. In general, management of ruminants is by communal herding of all livestock species (sheep, goats, cattle and camels), which graze on areas of natural pasture, with each family supervising their own animals. Many farmers are only able to water their cattle, sheep and goats every second day during the dry season, and some water every third day, with only a few farmers managing to water their animals daily. Somalia economy is largely depends upon livestock accounting for about $40 \%$ of the national income. The UN Development Programme (UNDP) and the UN Food and Agricultural Organization (FAO) commended the formation of a Somali Livestock Board that could help the industry to meet the requirements of importing countries of disease-free livestock and meat 
products originating from Somalia. Although, gastrointestinal nematode infections can be treated by anthelmintic chemotherapy, however, treatment is costly and drug resistance has evolved in all major parasite species (Ross, 1997; Zajac and Gipson, 2000; Veale, 2002). Besides, small-holders or pastoralists may not easily detect the effects of internal parasites on their animals, because of the generally sub-clinical or chronic nature of the helminth infections (Soulsby, 1982; Urquhart, et al., 1996) and much economic loss in terms of animal productivity has already occurred (Kaplan, 2006; Tibbo, et al., 2006). The current cattle, sheep, and goat populations of Somaliland are approximately 4, 23, and 18 million, respectively (Unofficial records). These livestock are almost entirely managed by the resource-poor, small-holder farmers and pastoralists. However, they make a critical contribution to food self sufficiency for rural households by providing milk, meat, skin, manure and traction, as well as generating direct cash income. Despite the large livestock population of Somaliland, the economic benefits remain marginal due to unknown prevailing diseases, poor nutrition, poor animal production systems, reproductive inefficiency, management constraints and general lack of veterinary care. Moreover, there is no sufficient information on epidemiology of the gastrointestinal parasites of ruminant animals in the Somaliland where mixed crop-livestock production system is the main form of agriculture. Therefore, this study was performed to identify the important nematode of cattle, sheep and goats in a main district of Somaliland (Togdheer), and to determine factors affecting their epidemiology to obtain baseline data so as to design effective control options as the regional GIT nematodes prevailence will determine what to do and which measures should be followed for control of the disease and to identify the optimal times of the year for strategic worm control. 


\section{MATERIALS AND METHOD}

\section{Study Area:}

This study was carried out during July 2008 to April 2009 in a main district (Togdheer) of Somaliland (Northern of Somalia), including four main villages namely Berbera, Sheikh, Burao and Odweyne (Fig. 1). The areas differ in both topography and climate conditions.

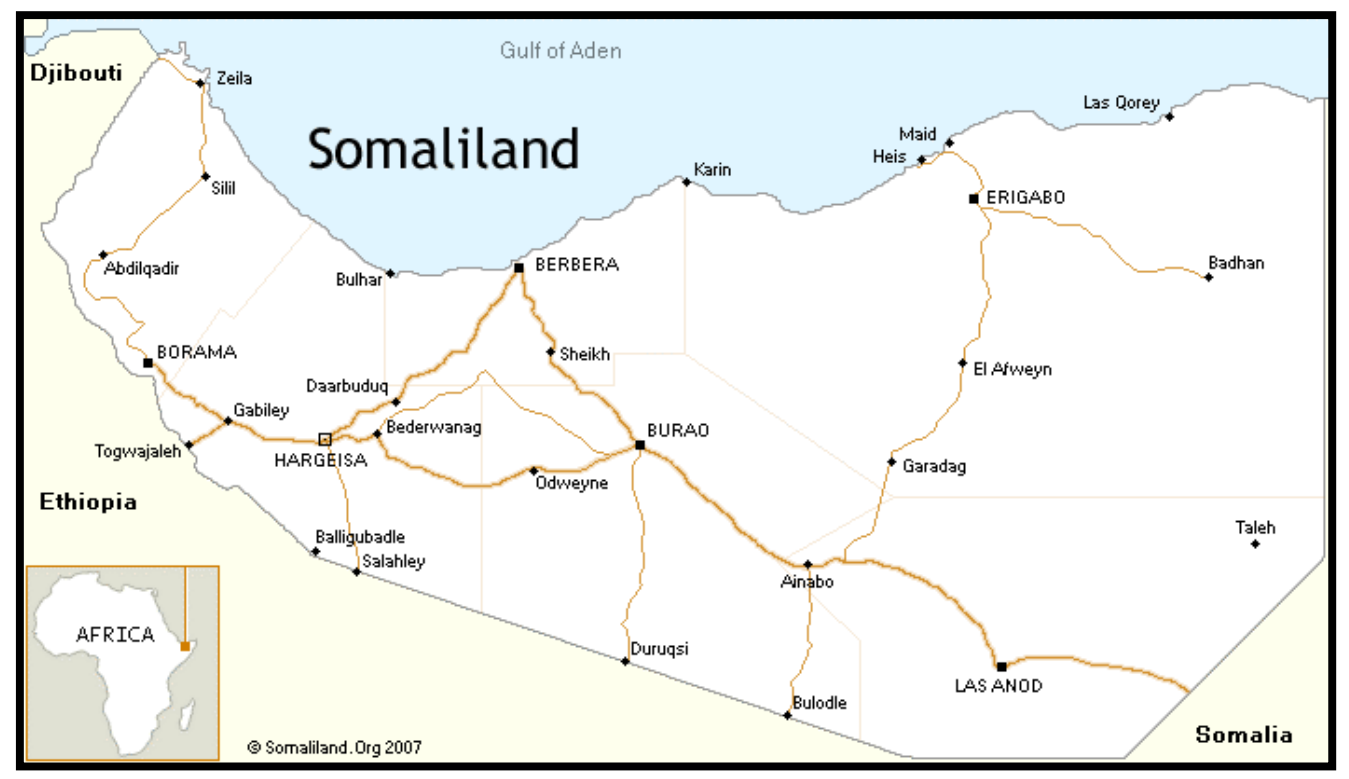

\section{Study Design:}

A random sampling procedure was used to select the animals and random fecal samples were collected directly from the rectum or recently defecated samples of the ground of a total of 1277 ruminants (389 cattle, 465 sheep, and 423 goats). The samples were collected in all seasonal conditions dry (May-October) and wet (November-May) from both sexes of all age groups of ruminants. One half of each collected sample were preserved in $10 \%$ formalin and the other half as fresh chilled and dispatched to Laboratory of the Gulf Veterinary International Quarantine Management Company, Berbera, Somaliland for coprological investigation. 


\section{Parasitological procedures:}

Fecal samples were taken directly from the rectum or the ground when the animal was seen defecating with strict sanitation using a gloved finger and placed in air and water tight sample vials, and then brought to the laboratory as fresh and as recent as possible. One half of each collected sample were preserved in $10 \%$ formalin and the other half as fresh chilled. In general, a minimum of 5-10 grams of faeces were used. The well-sealed fecal sample transferred in ice box as chilling the stool sample slows the development and hatching of any worm eggs and keeps the sample fresh out of direct sunlight. Parasitological examination was done by direct smear, sedimentation, flotation Modified McMaster and Baerman techniques following the standard procedures to identify and count eggs or larvae of parasitic helminthes according to Dunn, A. M., 1978; Soulsby, 1982; Hansen and Perry, 1994; Urquhart, et al., 1994; Urquhart, et al., 1996. Fecal cultures for identification of larvae $\left(\mathrm{L}_{3}\right)$ was based on specific morphological traits set by Poynter, 1970. Levels of worm infection were extrapolated from infection severity index defined by Soulsby, 1982 where horses are said to have mild, moderate, heavy and severe nematode infestation if their fecal egg counts are less than 500, 800-1000, 1100-1500 and more than 1500, respectively.

\section{Fecal floatation technique:}

Routine fecal floats were performed using sodium chloride solution (livestock). For protozoans (Eimeria species) using Sheather's Sugar solution. Fecal flotation by centrifugation to avoid overlooking parasitic eggs or larvae. using at least $2 \mathrm{~g}$ of feces for fecal flotation; $2 \mathrm{~g}$ of firm, normal feces. Preparing fecal samples for centrifugation, eliminate as 
much large debris as possible. First, add the fecal sample to an amount of flotation solution that will fill the tube into which the mixture will be poured to about $80 \%$ of its capacity. Stir the mixture to distribute the fecal material throughout the flotation solution. when sucrose was used, not to stir the mixture too vigorously to avoid creating air bubbles. Then pour the mixture through a strainer into another clean container and into a test tube or pour the mixture through one or two layers of gauze sponge into another clean container or directly into a test tube. The filtrate is ready for centrifugation. Centrifugal flotation was performed by using a fixed-angle centrifuge. Centrifuge the sample at about 1,200 rpm for five minutes. Faster centrifuge rates can be used without adversely affecting the result. Allow the centrifuge to stop. Remove the centrifuge tube, place it in a holder, and add flotation solution to form a meniscus. Follow the same procedure for placing a coverslip. Allow the sample to stand for a minimum of 10 minutes before removing the coverslip, placing it on a slide, and examining it for parasite stages. If a sucrose flotation solution is used, we have found that it may be necessary to allow the tube and coverslip to stand for 15 to 20 minutes to recover all of the parasites stages. Examine the coverslip on the slide systematically and thoroughly with the $10 \times$ objective lens (total magnification 100x). Small parasites or other objects should then be examined with the $40 \times$ objective lens (total magnification $400 \times$ ).

\section{Fecal egg counts:}

Numbers of Fecal nematode eggs were determined using a modified McMaster technique with saturated sodium chloride solution as the floating medium (Anon,1986; Hansen and Perry, 1994; Urquhart, et al., 
1994; Kassai, 1999). Those fecal samples that were positive for strongyles were subjected to egg output (eggs per gram; EPG) of feces count using McMaster egg counting technique (Hansen and Perry, 1994; ShahFischer and Say, 1989) and the degree of infestation was categorized based on literature (Shah-Fischer and Say, 1989; Solusby, 1982). In each case, $3 \mathrm{~g}$ of faeces were mixed in $42 \mathrm{ml}$ of saturated salt solution, and the number of nematode eggs per gram of faces (EPG) was obtained by multiplying the number of nematode eggs counted in two squares of the McMaster slide by a dilution factor of 50 (Anon, 1986; Hansen and Perry, 1994; Urquhart et al., 1994; Kassai, 1999). The nematode eggs present were identified in general terms as strongylid eggs, since relevant nematode genera produce eggs that are similar in appearance and cannot be discriminated easily, except for the eggs of Nematodirus, Strongyloides and Trichuris species.

\section{Fecal culture:}

Prevalence of gastrointestinal parasites was estimated using flotation in saturated $\mathrm{NaCl}$ and sedimentation methods. In order to assess species of gastrointestinal nematodes, infective (L3) larvae were cultured using samples of faeces from individual animals. Fecal samples weighing between 2 and $5 \mathrm{~g}$ from each cattle, goat or sheep in the study were prepared into a Fecal culture for third stage larvae development (Christie and Jackson, 1982). After 7 days of incubation larvae from Fecal cultures were harvested and identified to genera or species using light microscope. Three grams of feces were examined for lungworm larvae, using a modified Baerman analysis (Henriksen, 1965). 


\section{RESULTS}

The prevalence of gastrointestinal parasites in studied ruminants (cattle, sheep and goats) where highest for Strongyle (Trichsrtongylus Axei) 343 (26.9\%), followed by Lungworm (Dictyocaulus Filaria) 125 (9.8\%), Eimeria (Coccidia) 92 (7.2\%), Ascaris (Neoscaris vitulorum) 14 (3.6\%), and Homonchus Contortus 30 (2.3\%) respectively (Table 1). For cattle, the overll parasitic prevalence was 120 (30.9\%) with highest prevalence by stongyle 89 (22.9\%), followed by Ascaris 14 (3.6\%), Lungworm 9 (2.3\%) and Homonchus 8 (2.1\%) respectively. For sheep, the overll parasitic prevalence was $282(60.7 \%)$ with highest prevalence by stongyle 142 (30.5\%), followed by Lungworm 83 (17.8\%) Eimeria 43 (9.3\%), and Homonchus 14 (2.6\%) respectively. For goats, the overll parasitic prevalence was $202(47.8 \%)$ with highest prevalence by stongyle 112 (26.5\%), followed by Eimeria 49 (11.6\%), Lungworm 33 (7.8\%) and Homonchus 8 (1.9\%) respectively. Regarding study regions, the highest prevalence were in Odweyne 149 (54.2\%), Burao 213 (50.2\%), Sheikh 156 (45.1), followed by Berbera 86 (37.1\%) respectively (Table 2). As for sex, all species overall prevalence for females were higher $342(51.1 \%)$ than that of males $262(43.1 \%)$. For cattle, females were $69(34.3 \%)$ and males 51 (27.1\%). For sheep, females $161(63.9 \%)$ and males $121(56.8 \%)$. For goats, females 112 $(51.9 \%)$ and males $90(43.5 \%)$ however, the higher prevalence in females was not so significant (Table 3 ). The severity of infestation in relation to species where for examined 1277 animals (Table 4), overall prevalence was $47.3 \%(n=604)$, low was $62.9 \% \quad(n=380)$, moderate $26.7 \%(n=161)$, and severe was $10.4 \%(n=63)$. Cattle examined were 389 with over all prevalence of $30.9 \%(n=120)$ where the low degree was 
An Epidemio-Coprological Study Of Protozoan And ...

$68.3 \%(\mathrm{n}=82)$, moderate $25.0 \%(\mathrm{n}=30)$ and severe was $6.7 \%(\mathrm{n}=8)$. Sheep examined were 465 with over all prevalence of $60.7 \%(n=282)$ where the low degree was $61.7 \%(n=174)$, moderate $28.4 \%(n=80)$ and severe was $9.9 \%(n=28)$. Goats examined were 423 with over all prevalence of $47.8 \%(n=202)$ where the low degree was $61.4 \%(n=124)$, moderate $25.2 \%(n=51)$ and severe was $13.4 \%(n=27)$. EPG\% vary among studied regions with high degree (severe) in Burao 6.1\% $(\mathrm{n}=26)$ regions (highest than other regions and lowest severity ere found in Berbera region $3.5 \%(n=8)$ (Table 5$)$. EPG\% vary between males and females with little significance (Table 6). EPG\% vary between Dry season (May to October) and wet season (November to April) with significant variance as it was much higher in wet season $54.1 \%(n=457)$ than in dry season $34.0 \%(n=147)$ (Table 7).

Table (1): Prevalence of Gastrointestinal Parasites in Study Ruminants.

\begin{tabular}{||c|c|c|c|c|c|c|c||}
\hline \multicolumn{7}{|c|}{ Type of parasites (\%) } \\
\hline Species & $\begin{array}{c}\text { Total } \\
\text { animals } \\
\text { examined }\end{array}$ & $\begin{array}{c}\text { Ascaris } \\
\text { Neoscaris } \\
\text { vitulorum }\end{array}$ & $\begin{array}{c}\text { Eimeria } \\
\text { Coccidia }\end{array}$ & $\begin{array}{c}\text { Strongyle } \\
\text { Trichsrtongylus } \\
\text { Axie }\end{array}$ & $\begin{array}{c}\text { Lungworm } \\
\text { Dictyocaulus } \\
\text { Filaria }\end{array}$ & $\begin{array}{c}\text { Homonchus } \\
\text { Contortus }\end{array}$ & $\begin{array}{c}\text { Total } \\
\text { species } \\
\text { prevalence }\end{array}$ \\
\hline \hline Cattle & 389 & $14(3.6)$ & - & $9(2.3)$ & $89(22.9)$ & $8(2.1)$ & $120(30.9)$ \\
\hline Sheep & 465 & - & $43(9.3)$ & $83(17.8)$ & $142(30.5)$ & $14(2.6)$ & $282(60.7)$ \\
\hline Goat & 423 & - & $49(11.6)$ & $33(7.8)$ & $112(26.5)$ & $8(1.9)$ & $202(47.8)$ \\
\hline \hline Total & $\mathbf{1 2 7 7}$ & $\mathbf{1 4}(\mathbf{3 . 6})$ & $\mathbf{9 2 ( 7 . 2 )}$ & $\mathbf{1 2 5}(\mathbf{9 . 8})$ & $\mathbf{3 4 3}(\mathbf{2 6 . 9})$ & $\mathbf{3 0}(\mathbf{2 . 3})$ & $\mathbf{6 0 4}(\mathbf{4 7 . 3})$ \\
\hline
\end{tabular}

Table (2): Prevalence of Gastrointestinal parasites in relation to study regions.

\begin{tabular}{|c|c|c|c|c|c|c|c|c|}
\hline \multirow{2}{*}{ District } & \multicolumn{2}{|c|}{ Cattle } & \multicolumn{2}{|c|}{ Sheep } & \multicolumn{2}{|c|}{ Goat } & \multicolumn{2}{|c|}{ Total Prevalence } \\
\hline & Examined & $\%$ & Examined & $\%$ & Examined & $\%$ & Examined & $\%$ \\
\hline Berbera & 68 & $17(25.0)$ & 88 & $38(43.2)$ & 76 & $31(40.8)$ & 232 & $86(37.1)$ \\
\hline Sheikh & 102 & $31(30.4)$ & 132 & $82(62.1)$ & 112 & $43(38.4)$ & 346 & $156(45.1)$ \\
\hline Burao & 130 & $42(32.3)$ & 174 & $112(64.4)$ & 120 & $59(49.2)$ & 424 & $213(50.2)$ \\
\hline Odweyne & 89 & $30(33.7)$ & 71 & $50(70.4)$ & 115 & $69(60.0)$ & 275 & $149(54.2)$ \\
\hline All districts & 389 & $120(30.9)$ & 465 & $282(47.8)$ & 423 & $202(47.8)$ & 1277 & $604(47.3)$ \\
\hline
\end{tabular}


Table (3): Prevalence of gastrointestinal parasites in relation to sex.

\begin{tabular}{|c|c|c|c|c|c|c|c|}
\hline \multirow{2}{*}{ Sex } & \multicolumn{2}{|c|}{ Cattle } & \multicolumn{2}{|c|}{ Sheep } & \multicolumn{2}{|c|}{ Goat } & \multirow{2}{*}{ Total } \\
\hline & Examined & Prevalence \% & Examined & Prevalence \% & Examined & Prevalence \% & \\
\hline Male & 188 & $\overline{51(27.1)}$ & 213 & $121(56.8)$ & 207 & $90(43.5)$ & $7608262(43.1)$ \\
\hline Female & 201 & $69(34.3)$ & 252 & $161(63.9)$ & 216 & $112(51.9)$ & $669342(51.1)$ \\
\hline Total & 389 & $120(30.9)$ & 465 & $282(60.7)$ & $\overline{423}$ & $202(47.8)$ & $1277604(4.3)$ \\
\hline
\end{tabular}

Table (4):Prevalence of gastrointestinal parasites and EPG(Egg Per Gram)degree.

\begin{tabular}{|c|c|c|c|c|c|}
\hline \multicolumn{6}{|c|}{ EPG\% } \\
\hline Species & Examined Animals & Overall Prevalence & low & Moderate & Severe \\
\hline Cattle & 389 & $120(30.9)$ & $82(68.3)$ & $30(25.0)$ & $8(6.7)$ \\
\hline Sheep & 465 & $282(60.7)$ & $174(61.7)$ & $80(28.4)$ & $28(9.9)$ \\
\hline Goat & 423 & $202(47.8)$ & $124(61.4)$ & $51(25.2$ & $27(13.4)$ \\
\hline Total & 1277 & $604(47.3)$ & $380(62.9)$ & $161(26.7)$ & $63(10.4)$ \\
\hline
\end{tabular}

Table (5): Degree of EPG\% in relation to Study Regions.

\begin{tabular}{|c|c|c|c|c|c|}
\hline \multicolumn{6}{|c|}{ EPG\% } \\
\hline District & Examined Animals & Overall Prevalence & low & Moderate & Severe \\
\hline Berbera & 232 & $86(37.1)$ & $59(25.4)$ & $19(8.2)$ & $8(3.5)$ \\
\hline Sheikh & 346 & $156(45.1)$ & $111(32.1)$ & $29(8.4)$ & $16(4.6)$ \\
\hline Burao & 424 & $213(50.2)$ & $134(31.6)$ & $53(12.5)$ & $26(6.1)$ \\
\hline Odweyne & 275 & $149(54.2)$ & $76(27.6)$ & $60(21.8)$ & $13(4.7)$ \\
\hline Total & 1277 & $604(47.3)$ & $380(62.9)$ & $161(26.7)$ & $63(10.4)$ \\
\hline
\end{tabular}

Table (6): Prevalence and degree of EPG\% of gastrointestinal parasites in relation to sex.

\begin{tabular}{|c|c|c|c|c|c|}
\hline \multicolumn{6}{|c|}{ EPG\% } \\
\hline Sex & Total Examined No. & Total Prevalence & low & Moderate & Severe \\
\hline Male & 608 & $262(43.1)$ & $184(30.3)$ & $73(12.5$ & $29(4.8)$ \\
\hline Female & 669 & $342(51.1)$ & $196(29.3)$ & $88(13.2)$ & $34(5.1)$ \\
\hline Total & 1277 & $604(4.3)$ & $380(62.9)$ & $161(26.7)$ & $63(10.4)$ \\
\hline
\end{tabular}

Table (7): Prevalence and degree of EPG\% of gastrointestinal parasites in relation to Seasons.

\begin{tabular}{||c|c|c|c|c|c||}
\hline \multicolumn{7}{|c|}{ EPG\% } & Moderate & Severe \\
\hline \hline $\begin{array}{c}\text { Sex } \\
\text { Dry } \\
\text { (May-October) }\end{array}$ & 432 & $147(34.0)$ & $77(52.4)$ & $28(19.0)$ & $13(8.8)$ \\
\hline $\begin{array}{c}\text { Wet } \\
\text { (November-April) }\end{array}$ & 845 & $457(54.1)$ & $303(66.3)$ & $133(29.1)$ & $50(10.9)$ \\
\hline \hline Total & 1277 & $604(47.3)$ & $380(62.9)$ & $161(26.7)$ & $63(10.4)$ \\
\hline
\end{tabular}

Kafrelsheikh Vet. Med. J. Vol. 7 No. 1 (2009) 


\section{DISCUSSION}

This study revealed that the overall prevalence of gastrointestinal parasites of ruminants was $69.6 \%$ and $50.2 \%, 75.3 \%$, and $84.1 \%$ in cattle, sheep and goats, respectively. It also revealed that regardless of the species of ruminants, the animals are infected with variety of parasites of which strongyle $26.9 \%(\mathrm{n}=343)$ and Lungworm $9.8 \%(\mathrm{n}=125)$ are the most abundant. In addition, the results of the composite Fecal cultures revealed that $H$. contortus was the least dominant nematode species of cattle, sheep, and goats representing $2.3 \%(n=30)$ of the total larval recovery from cultures throughout the entire study period. The percentage of this parasite was highest during the time of the highest Fecal egg counts in the wet seasons. Other observed results, of highest EPGs with the largest percentages of $H$. contortus L3 in Fecal cultures during the rainy seasons, were in accordance with studies in other countries in Africa with distinct rainy and dry seasons (Ghana: Agyei, 1991; Kenya: Maingi, et al., 1993; Nginyi, et al., 2001; Zimbabwe: Pandey, et al., 1994). In addition, overstocking, which is a major problem in many African communal pastures may have contributed to the observed increased availability of infective larvae of GI nematodes on pasture during the wet season (Hansen and Perry, 1994). However, my findings were similar to other epidemiological studies on nematode parasites of small ruminants in semi-arid regions of Africa, where inhibition of $H$. contortus is a feature during the dry periods of the year (Kenya: Allonby and Urquhart, 1975; Nigeria: Ogunsusi and Eysker, 1979; Senegal: Vercruysse, 1985; Nigeria: Chiejina, et al., 1988; Zimbabwe: Pandey, et al., 1994). Trichostrongylus spp. were the most prevalent parasites, which represented $26.3 \%$ of the total infective larvae harvested from the 
composite Fecal cultures during the study period. Similar prevalence rate was reported in some parts of Ethiopia (Tesfaye, 1998) and Kenya (Maichomo, et al., 2004) but slightly lower than prevalence in sheep and goats from eastern part of Ethiopia (Abebe and Esayas, 2001) and Zimbabwe (Moyo, et al., 1996). The overall prevalence in all study regions were the same in sheep $47.8 \%(n=282)$ and goats $47.8 \%(n=202)$, however, it contradicts the assumption of earlier works in some part of Ethiopia (Teklye, 1991) and Kenya (Waruiru, et al., 2005) as neighbouring counteries to Somaliland where higher parasite prevalence is more common in sheep than in goats due to the grazing habit of sheep. The degree of EPG in most of the study animals was low (Table 4), agreeing with various works (Deressa, 1998; Maichomo, et al., 2004) indicating the sub-clinical cases of gastrointestinal parasites with subsequent subsistent low degree of pasture contamination. But it is inconsistent with reports from eastern Ethiopia (Abebe and Esayas, 2001) that could be explained by the difference in management and breed of the respective animals. These agro-ecologic zones are characterized by a hot-humid environmental situation that is favorable for the survival of the infective larval stage of most of the parasites. The influences of the sex and age of the animals on nematode worm burdens was not significant, but the worm burdens during the wet seasons were significantly higher than during the dry seasons. The study further revealed that sex of the animal did not show significant association with the prevalence of the parasites and degree of EPG (Table 6). These seasonal variations in the nematode worm burdens were similar to studies in other tropical countries with distinct rainy and dry seasons (Fritsche, et al., 1993; Nginyi, et al., 2001; Magona and Musisi, 2002; Tsotetsi and Mbati, 2003; Nwosu, et al., 2006). In general, moist and warm environmental conditions are 
favourable for the development, survival and transmission of the preparasitic stages of parasitic nematodes (Donald, 1968; Hansen and Perry, 1994; Urquhart, et al., 1996). The absence of association between sex and prevalence of EPG is in agreement with that of Keyyu, et al., 2003. The higher degree of EPG were recorded in wet season than in drier ones $54.1 \%$ and $34.0 \%$ respectively. This finding is in consent with many reports around the world. (Tembely, et al., 1997; Tembely, et al., 1998; Moyo, et al., 1996; Fritsche, et al., 1993; Pandey, et al., 1993; Nwosu, et al., 1996; Nginyi, et al., 2001; Kumba, et al., 2003; $\mathrm{Ng}^{\prime} \mathbf{a n g}^{\prime} a$, et al., 2004; Githigia, et al., 2005). This is due to the existence of a direct relationship between prevalence with the humidity and temperature. In this study, the presence of sufficient moisture during the rainy season favored the survival of infective larvae in the pasture and higher probability of uptake of the infective larvae leading to higher prevalence rate. There was no significant difference in the prevalence due to age. This observation is in consent with previous works in Ethiopia and Kenya (Githigia, et al., 2005) that stated no association of degree of EPG and age of the animals But it is to the contrary from semi-arid parts of Kenya that reported higher prevalence and intensity of EPG in older sheep and goats (Waruiru, et al., 2005). But the findings of this study are inconsistent with reports from Gambia where adults and older animals bear high worm burden (Fritsche, et al., 1993) and in contrast to reports by Belem, et al., 2005 where, a significantly higher prevalence rate was recorded in younger animals (calves and lambs) and was also higher in kids. This finding also is in agreement with most literatures from different corner of the world (Dunn, 1978; Shah-Fischer and Say, 1989; Keyyu, et al., 2003; Nwosu, et al., 1996; $\mathrm{Ng}^{\prime} a n g ' a$, et al., 2004; 
Githigia, et al., 2005). This could be due to the fact that younger animals are more susceptible than adult counter parts. Adult animals may acquire immunity to the parasites through frequent challenge and expel the ingested parasite before they establish infection, (Dunn, 1978; Shah-Fischer and Say, 1989). Therefore, this study identified the potential risk factors associated with high prevalence rate and high degree of EPG enabling to design feasible and strategic control of helminth parasites of ruminants in areas of similar ecological features. In this study, important parasites of cattle, sheep and goats were identified, and those factors affecting the epidemiology of these parasites of ruminants in a main district of Somaliland (Togdheer) were elucidated. The present studies also demonstrated the roles of other factors (age, sex and susceptibility of host animals, parasite fecundity, stocking density, and agro-climatic zones) in the epidemiology of GI nematode of large and small ruminants in Somaliland. It is known that a prerequisite for the development and implementation of sustainable parasite management programs is to have an epidemiological knowledge of the parasites present in a specific area. The sustainability of helminth control practices also relies on the prevention of resistance and preservation of anthelmintic effectiveness, as well as effective utilization of the locally available feed resources. Thus, it is hoped that this study will provide a starting point for the development of epidemiologically based control strategies for GI nematode of small and large ruminants in Somaliland. Optimized anthelmintic usage to preserve anthelmintic efficacy and prevent resistance to occur in GI nematodes. Recommendations include the use of the most suitable drugs with correct dosage. Future research could include the relative importance of helminth parasites on productivity of small ruminants. 


\section{REFERENCES}

- Abebe, W., and Esayas, G., (2001). Survey on ovine and caprine gastro-intestinal helminthosis in eastern part of Ethiopia during the dry season of the year. Revue Vet Med.152(5):379-384.

- Agyei, A. D., Sapong, D., and Probert, A. J., (1991). Periparturient rise in Fecal nematode egg counts in west African dwarf sheep in southern Ghana in the absence of arrested strongyle larvae. Veterinary Parasitology 39, 79-88.

- Allonby, E. W., and Urquhart, G. M., (1975). The epidemiology and pathogenic significance of haemonchosis in a merino flock in east Africa. Veterinary Parasitology 1, 129-143.

- Anon, (1986). Manual of Veterinary Parasitological Laboratory Techniques. Reference Book. Her Majesty's Stationary Office, London. $160 \mathrm{pp}$.

- Anon, (1994). Diseases of Domestic Animals Caused by Flukes: Epidemiology, Diagnosis and Control of Fasciola, Paramphistome, Dicrocoelium, Eurytrema and Shistosome Infections of Ruminants in Developing Countries. FAO (Food and Agriculture Organization of the United Nations), Report. Rome, Italy. 49 pp.

- Anon, (1997). National Livestock Development Programme. Ministry of Agriculture (MoA), Animal and Fisheries Resource Development Department, Addis Ababa Ethiopia.

- Anon,(2000b). Small Ruminant Research Strategy.Ethiopian Agricultural Research Organisation(EARO). Animal Science Research Directorate, Addis Ababa, Ethiopia. 
- Assoku, R. K., (1981). Studies of parasitic helminths of sheep and goats in Ghana. Bulletin of Animal Health and Production in Africa 29, 1-10.

- Bekele, T., Woldeab, T., Lahlou-Kassi, A., and Sherington, J., (1992). Factors affecting morbidity and mortality on-farm and onstation in the Ethiopian highland sheep. Acta Tropica 52, 99-109.

- Belem, A. M. G., Kabore, A., and Bessin, R., (2005). Gastrointestinal helminthes of sheep in the central, eastern and northern parts of Burkina Faso. Bull Anim Health Prod Afr. 53(1):13-23.

- Chiejina, S. N., Fakae, B. B. and Eze, B. O., (1988). Arrested development of gastrointestinal trichostrongylids in goats in Nigeria. Veterinary Parasitology 28, 103-113.

- Chiejina, S. N., Fakae, B. B. and Eze, P. I., (1989). Development and survival of freeliving stages of gastrointestinal nematodes of sheep and goats on pasture in the Nigerian derived savanna. Veterinary Research and Communication 13, 103-112.

- Christie,M., and Jackson, F., (1982). Specific identification of strongyle eggs in small samples of sheep faeces. Reserarch in Veterinary Science, $32,113-117$.

- Cole, V. G., (1986). Helminth Parasites of Sheep and Cattle. Animal Health in Australia, Volume 8. Australian Agricultural Health and Quarantine Service, Department of Primary Industry, Canberra, pp255.

- Debela, E., (2002). Epidemiology of gastro-intestinal helminthiasis of Rift Valley goats under traditional husbandry system in Adami Tulu district, Ethiopia. Ethiopian Journal of Science 25, 35- 44. 
- Deressa, A., (1998). Economic importance of ovine helminth parasites at Sheno. Ethiopian Vet Association Proceedings of the 12th Conference. Addis Ababa, Ethiopia; June:43-51.

- Donald, A. D., (1968). Ecology of the free-living stages of nematode parasites of sheep. Australian Veterinary Journal 44, 139-144.

- Dryden, M. W., Payne, P. A., and Ridley, R., (2005). Comparison of common fecal flotation techniques for the recovery of parasite eggs and oocysts. Vet Ther. 6:15-28.

- Dryden, M. W., Payne, P. A., and Smith, V., (2006). Accurate diagnosis of Giardia spp and proper fecal examination procedures. Vet Ther. 7:4-14.

- Dunn,A.M., (1978). Veterinary Helminthology. 2nd edition. London: William Heinemann Medical Books.

- Fakae, B. B., (1990). The epidemiology of helminthosis in small ruminants under the Traditional husbandry system in eastern Nigeria. Veterinary Research and Communication 14, 381-391.

- Fritsche, T., Kaufmann, J., and Pfister, K., (1993). Parasite spectrum and seasonal epidemiology of gastro-intestinal nematodes of small ruminants in the Gambia. Vet Parasitol. 49(2-4):271-283.

- Gatongi, P. M., Scott, M. E., Ranjan, S., Gathuma, J. M., Munyua, W. K., Cheruiyot, H., and Prichard, R. K., (1997). Effects of three nematode anthelmintic treatment regimes on flock performance of sheep and goats under extensive management in semi-arid Kenya. Veterinary Parasitology 68, 323-336. 
- Githigia, S. M., Thamsborg, S. M., Maingi, N., and Munyua, W. K., (2005). The epidemiology of gastrointestinal nematodes in Goats in the low potential areas of Thika District, Kenya. Bull Anim Health Prod Afr. 53(1):5-12.

- Hansen, J., and Perry, B., (1994). The Epidemiology, Diagnosis and Control of Helminth Parasites of Ruminants. A Handbook. 2nd ed. ILRAD (International Laboratory for Research on Animal Diseases), Nairobi, Kenya, 171 pp.

- Henriksen, S.A., (1965). En forbedret teknik ved undersøgelse for lungeormelarver i faeces. Nordic Veterinary Medicine 17: 446-454.

- Jubb, K. V. F., Kennedy, P. C., and Palmer, N., (1993). Pathology of Domestic Animals, Fourth Edition, Academic Press.

- Kaplan, M., (2006). Update on parasite control in small ruminants: Addressing the challenges posed by multiple-drug resistant worms. In: Proceedings of the American Association of Bovine Practitioners. Saint Paul, MN, USA, September 21-23.

- Kassai, T., (1999). Veterinary Helminthology. Butterworth-Heinemann, Reed Educational and Professional Publishing Ltd., Oxford, USA. 260 pp.

- Keyyu, J. D., Kassuku, A. A., Kyvsgaard, N. C., and Willingham, A. L., (2003). 3rd: Gastrointestinal nematodes in indigenous zebu cattle under pastoral and nomadic management systems in the lower plain of Southern highlands of Tanzania. Vet Res Commun. 27(5):371-380.

- Kumba, F. F., Katjivena, H., Kauta, G., and Lutaaya, E., (2003). Seasonal evolution of fecal egg output by gastrointestinal worms in goats on communal farms in eastern Namibia. Onderstepool $\mathrm{J}$ Vet Res. 70(4):265-271. 
- Magona, J. W. and Musisi, G., (2002). Influence of age, grazing system, season and agroclimatic zone on the prevalence and intensity of gastro-intestinal strongylosis in Ugandan goats. Small Ruminant Research 44, 187-192.

- Maichomo, M. W., Kagira, J. M., and Walker, J., (2004). Point prevalence of gastrointestinal parasites in calves, sheep and goats in Magadi division, Southwestern Kenya. Onderstepool J Vet Res. 71(4):257-261.

- Maingi, N., Gichanga, E. J., and Gichohi, V. M., (1993). Prevalence of gastrointestinal helminths and coccidian parasites and frequency distribution of some nematode genera of goats on some farms in four districts of Kenya. Bulletin of Animal Health and Production in Africa 41, 285-290.

- McLeod, R. S., (1995). Cost of major parasites to the Australian livestock industries. International Journal for Parasitology 25: 13631367.

- Moyo, D. Z., Bwangamoi, O., Hendrikx, W. M., and Eysker, M., (1996). The epidemiology of gastrointestinal nematodes infections in communal cattle and commercial beef cattle on the highveld of Zimbabwe. Vet Parasitol. 67(1-2):105-120.

- Nari, A., Salles, J., Castell, D., and Hansen, J. W., (1997). Control of gastro-intestinal nematodes in farming systems of Uruguay. In: Hansen, J. W., Waller P. J. (Eds.), Proceedings of Biological Control Workshop. FAO Technical Series Report No. 141. pp. 89-94. 
- Ng'ang'a, C. J., Maingi, N., Munyua, W. K., and Kanyari, P. W., (2004). Epidemiology of gastrointestinal helminths infection in Dorper sheep in semi-arid area of Kenya. Ondestepool J Vet Res. 71(3):219-226.

- Ngategize, P. K. J., Bekele, T., and Tilahun, G., (1993). Financial losses caused by ovine fascioliasis in the Ethiopian highlands. Tropical Animal Health and Production 25, 155-161.

- Nginyi, J. M., Duncan, J. L., Mellor, D. J., Stear, M. J., Wanyangu, S. W., Bain, R. K., and Gatongi, P. M., (2001). Epidemiology of parasitic gastro-intestinal nematode infections of ruminants on smallholder farms in central Kenya. Research in Veterinary Science 70, 33-39.

- Nwosu, C. O., Madu, P. P., and Richards, W. S., (2006). Prevalence and seasonal changes in the population of gastro-intestinal nematodes of small ruminants in the semi-arid zone of north-eastern Nigeria. Veterinary Parasitology (in press).

- Nwosu, C. O., Ogunrinade, A. F., and Fagbemi, B. O., (1996). Prevalence and seasonal changes in the gastrointestinal helminths of Nigerian goats. J Helminthol. 70:329-333.

- O'Connor, L. J., Walkden-Brown, S. W., and Kahn, L. P., (2006). Ecology of the freeliving stages of major trichostrongylid parasites of sheep. Veterinary Parasitology 142, 1-15.

- Ogunsusi, R. A., and Eysker, M., (1979). Inhibited development of trichostrongylids of sheep in northern Nigeria. Research in Veterinary Science 26, 108-110. 
- Over, H. J., Jansen, J., and Von Olm, P. W., (1992). Distribution and Impact of Helminth Diseases of Livestock in Developing Countries. FAO Animal Production and Health Paper 96. FAO (Food and Agriculture Organization of the United Nations), Rome, Italy, pp. 221.

- Pandey, V. S., Chitate, F., and Nyanzunda, T. M., (1993). Epidemiological observations on gastrointestinal nematodes in communal land cattle from the highveld of Zimbabwe. Vet Parasitol. 51:99-106.

- Pandey, V. S., Ndao, M., and Kumar, V., (1994). Seasonal prevalence of gastrointestinal nematodes in communal land goats from the highveld of Zimbabwe. Veterinary Parasitology 51, 241-248.

- Payne, P. A., and Dryden, M. W., (2003). Accurate evaluation of fecal samples critical to patient. DVM Best Practices. 8-11.

- Perry, B. D., and Randolph, T. F., (1999). Improving the assessment of the economic impact of parasitic diseases and of their control in production animals. Veterinary Parasitology 84, 145-168.

- Perry, B. D., Randolph, T. F., McDermott, J. J., Sones, K. R., and Thornton, P. K., (2002). Investing in Animal Health Research to Alleviate Poverty. International Livestock Research Institute (ILRI), Nairobi, Kenya, pp. 148.

- Poynter, D., (1970). Some observations on the nematode parasites of horses. In: Bryans J T Gerber H (editors), Equine Infectious Diseases. Proceedings 2nd International Conference on Equine Infectious Diseases, Paris, (Basel, Switzerland, S.Karger), Pp. 269-289.

- Ross, M. H., (1997). The role of drugs in the control of parasitic nematode infections: must we do without. Parasitology, 114, 137-144. 
- Shah-Fischer,M., and Say, R., (1989). Manual of Tropical Veterinary Parasitology. CAB International; The Technical Center for Agricultural and Rural Cooperation (CTA).

- Smeal, M. G., (1995). Parasites of Cattle, Veterinary Review No.32, The University of Sydney, Post Graduate foundation in Veterinary Science, pp358.

- Soulsby, E. J. L., (1982). Helminths, Arthropods and Protozoa of Domesticated Animals, 7th Ed. The English Language Book Society and Ballière Tindall, London, 809 pp.

- Teklye, B., (1991). Epidemiology of endoparasites of small ruminants in sub-saharan Africa. Proceedings of Fourth National Livestock Improvement Conference. Addis Ababa, Ethiopia; 13-15 November 711.

- Tembely, S., (1998). Development and survival of infective larvae of nematode parasites of sheep on pasture in a cool tropical environment. Veterinary Parasitology 79, 81-87.

- Tembely, S., Lahlou-Kassi, K., and Rege, J. E., (1998). Breed and season effects on the peri-parturient rise in nematode egg output in indigenous ewes in a cool tropical environment. Vet Parasitol. 77(23):123-132.

- Tembely, S., Lahlou-Kassi, K., Rege, J. E., Sovani, S., Diedkiou, M. L., and Baker, R. L., (1997). The epidemiology of nematode infections in sheep in a cool tropical environment. Vet Parasitol. 70(13):129-141. 
- Tesfaye, H., (1998). Ovine and bovine helminthiasis in Kelala (S. Wollo). Ethiopian Vet Association Proceedings of the $12^{\text {th }}$ Conference. Addis Ababa, Ethiopia; June :30-34.

- Tibbo, M., Aragaw, K., Philipsson, J., Malmfors, B., Nasholm, A., Ayalew, W., and Rege, J. E. O., (2006). Economics of sub-clinical helminthosis control through anthelmintics and nutrition in indigenous Menz and Awassi-Menz crossbred sheep in Ethiopia. Unpublished.

- Tilahun, G., (1993). A survey of fascioliasis in cattle, sheep and goats slaughtered at Addis Ababa abattoir. In: Arosenius, C., Jacobsen, L., Lindberg, R. and Nilsson, P. O. (Eds.), Animal Diseases of the Gastrointestinal Tract and Liver: An African Perspective. Proceedings of a seminar held at ILCA (International Livestock Centre for Africa), Addis Ababa, Ethiopia, pp 125-133.

- Tilahun, G., (1995). Epidemiology of helminth parasites of small ruminants in midlowland Ethiopia. In: Gray, G. D., Uilenberg, G. and Jacobsen, L. L. (Eds.), Parasitology Research in Africa. Proceedings of an IFS (International Foundation for Science) workshop, BoboDioulasso, Burkina Faso, pp 255-269.

- Torina, A., Ferrantelli, V., Sparagano, O. A., Reale, S., Vitale, F., and Caracappa, S., (2004). Climatic conditions and gastro-intestinal nematode egg production: observations in breeding sheep and goats. Annals of New York Academy of Science 1026, 203-209.

- Tsotetsi, A. M., and Mbati, P. A., (2003). Parasitic helminths of veterinary importance in cattle, sheep and goats on communal farms in the north-eastern Free State, South Africa. Journal of South African Veterinary Association 74, 45-48. 
- Urquhart, G. M.,Armour,J., Duncan,J.L.,Dunn,A. M., and Jennings, F. W.,(1994). Veterinary Parasitology. $1^{\text {st }}$ edition. Singapore; Longmann.

- Urquhart, G. M., Armour, J., Duncan, J. L., Dunn, A. M., and Jennings, F. W., (1996). Veterinary Parasitology, 2nd ed. Blackwell Science, United Kingdom, p. 307.

- Van Wyk, J. A., Cabaret, J., and Michael, L. M., (2004). Morphological identification of nematode larvae of small ruminants and cattle simplified. Veterinary Parasitology 119, 277-306.

- Veale, P. I., (2002). Resistance to macrocyclic lactones in nematodes of goats. Australian Veterinary Journal, 80, 303-304.

- Vercruysse,J., (1985). The seasonal prevalence of inhibited development of Haemonchus contortus in sheep in Senegal. Veterinary Parasitology 17, 159-163.

- Waruiru, R. M., Mutune, M. N., and Otieno, R. O., (2005). Gastrointestinal parasite infections of sheep and goats in a semi-arid area of Machakos District, Kenya. Bull Anim Health Prod Afr. 53(1):25-34.

- Zajac, A. M., (2006). Gastro-intestinal nematodes of small ruminants: life cycle, anthelmintics, and diagnosis. Veterinary Clinics, Food Animal Practice 22, 529-541.

- Zajac, A. M., and Gipson, T. A., (2000). Multiple anthelmintic resistance in a goat herd. Veterinary Parasitology, 87, 163-172. 